\title{
Pattern of Pediatric Surgical Admissions in a Combined Military Hospital Nessa $\mathrm{M}^{1}$, Dewan $\mathrm{MAH}^{2}$ \\ DOI: https://doi.org/10.3329/jafmc.v14i2.45886
}

\begin{abstract}
Introduction: Pediatric surgical admissions are daily practice at peripheral hospital. To design strategy for appropriate diagnosis and management of pediatric surgical patient reported to combined military hospital (CMH) Bogura, Bangladesh.
\end{abstract}

Objectives: To find out the pattern of pediatric surgical admission cases and factors affecting their outcomes.

Methods: This case series analysis was conducted from November 2016 to October 2017 at CMH, Bogura. Total 175 patients admitted during this period out of them 13 children excluded from study due to parent's refusal for intervention or discharged against medical advice. In this study total 162 admitted children's data were analyzed.

Results: The study showed emergency cases were predominating $74.69 \%$ and elective cases were less common $25.30 \%$. Mortality recorded exclusively in children admitted on emergency basis 6 children (3.70\%). Congenital anomaly of GIT was found the leading causes of death in this study $4(2.46 \%)$ children.

Conclusion: Many emergency and elective pediatric surgical patients can be managed at peripheral Hospital with acceptable outcomes except the neonate.

Key-words: Pediatric surgical admissions, Peripheral hospital, Emergency cases.

\section{Introduction}

The recent decades witnessed a tremendous growth in the field of medicine, especially in the area of sub-specialization in surgery ${ }^{1,2}$. Pediatric surgery is one of the demanding surgical disciplines. Children are not young adult but are a group with specific attributes that necessitate special care and attention ${ }^{3}$. Comprehensive care of the pediatric surgical patient is multifaceted and requires a thorough understanding of the surgical diseases encountered, a detailed knowledge of the physiology of the pediatric population, and an awareness of the unique issues inherent in providing medical care for children $^{3,4}$. The surgeon must obtain a complete and detailed history from the patient and parents. The history, in concert with a well-performed physical examination, is the basis for a diagnosis and treatment plan ${ }^{5}$.

Surgical cares for pediatric patients in developing countries is said to be too expensive to deliver mainly due to economical constraints and burden of non-surgical illnesses ${ }^{6}$. Usually the pattern of pediatrics surgical admission at peripheral hospital is poorly documented. So that mortality, morbidity and factors affecting the outcomes were difficult for analysis despite many children with surgical illness have been managed at these levels. The same as Bangladesh tertiary level hospitals, many sick children were found coming to peripheral hospitals with variety of surgical diseases. About three decades ago, Belachew $^{7}$ analysis gave much emphasis on three common surgical disease (intussusceptions, inguinal hernia and appendicitis), at tertiary hospital level. A study conducted by Abebe $^{8}$ did not separately analyze pediatric surgical diseases. Miliard's study ${ }^{6}$ was to the point; however, pediatric surgical cases managed in a tertiary hospital with much better setup could not represent peripheral hospitals. In other words, for a known fact, the finding in tertiary hospital can not be generalized. The object of this study is to analyze pattern of pediatric surgical admission at peripheral hospital of Armed Forces with emphasis on common cases and factors affecting the outcome.

\section{Materials and Methods}

This is a case series study conducted on pediatric surgical patients admitted from November 2016 to October 2017 in combined military hospital $(\mathrm{CMH})$, Bogra. During the study period, a total of 936 children admitted to the hospital out of which $175(18.69 \%)$ were admitted with surgical illnesses. There were 13 parents who refused and failed to give consent for surgical interventions, and as result, these cases were discharged against medical advice and as well excluded from the study. For 162 cases surgical pediatric patients, either of the parent or close family member signed consent for both the surgical interventions and being involved in the study Variables included were diagnosis, treatment and out come. Data collecting format was structured as open ended and administered/interviewed by two surgeons including the author prior and after the procedure. Completeness and consistencies of data were being checked and revised for errors during data collection. Data were analysis by Window Microsoft Excel and summarized and presented as simple frequency tables.

\section{Results}

Among the 162 patients $122(75.30 \%)$ were male and $40(24.69 \%)$ were female with a male to female ratio 
3.04:1. The age range of these children were from 1 day to $9 \mathrm{yrs}$. Leading cause of admission was extremity trauma 20(12.34\%) followed by scald and burn injury $18(11.11 \%)$, acute appendicitis $16(9.87 \%)$, then head injury, inguinal hernia, phimosis and foreign body ingestion 15 (9.25\%) each (Table-I). Among the patients, emergency admission was $121(74.67 \%)$ and $41(25.33 \%)$ were routine admission (Table-II). Operative management was done for $119(73.45 \%)$ children out of them $69(42.59 \%)$ were emergency operation and $43(26.54 \%)$ children were managed conservatively (Table-III). Among the 119 surgically managed cases only $12(10.08 \%)$ developed complications. Complication was surgical site infection 6(5.04\%), hematoma and wound dehiscence 3(2.52) each (Figure-1). Patients' outcomee after management are shown in Table-IV. Among 162 patient total mortality was $6(3.70 \%)$ among them 2 were gastroschisis and 1 intestinal atresia.

Table-I: Total admitted children with diagnosis, sex ratio, age range and average age $(n=162)$.

\begin{tabular}{|l|r|r|r|r|}
\hline \multirow{2}{*}{ Diagnosis } & Total & Sex Ration & \multicolumn{2}{c|}{ Age } \\
\cline { 4 - 5 } & Patients & M:F & \multicolumn{1}{c|}{ Range } & Average \\
\hline Acute Appendicitis & 16 & $4.33: 1$ & $4-7.2$ year & 5.1 year \\
\hline Appendicular lump & 7 & $2.5: 1$ & $5-6.8$ year & 6.2 year \\
\hline Blunt trauma abd & 3 & $2: 1$ & $6-8$ year & 7 year \\
\hline Calculous cholecystitis & 5 & $1.5: 1$ & $8-10.2$ year & 9.2 year \\
\hline Cholelithiasis & 3 & $2: 1$ & $9-11$ year & 10 year \\
\hline Extremity trauma & 20 & $1.5: 1$ & $4-7$ year & 5.3 year \\
\hline Foreign body swallow & 15 & $2: 1$ & $2-12$ year & 4.06 year \\
\hline Head injury & 15 & $4: 1$ & $2.6-7.6$ year & 5.1 year \\
\hline Inguinal hernia & 15 & $15: 0$ & $3-7.3$ year & 5.1 year \\
\hline Intussusception & 3 & $1: 2$ & $11-14$ month & 12.33 mot \\
\hline Omphalocele & 3 & $2: 1$ & $1-3$ days & 2 days \\
\hline Parapjhimosis & 5 & $5: 0$ & $3-4$ year & 3.4 year \\
\hline Phimosis & 15 & $15: 0$ & $1.5-4$ year & 2.5 year \\
\hline Scald burn injury & 18 & $2: 1$ & $1.1-6.5$ year & 3.8 year \\
\hline Tongue tie & 8 & $3: 1$ & $0.5-9$ year & 3.03 year \\
\hline UDT & 3 & $3: 0$ & $3-5$ year & 4 year \\
\hline
\end{tabular}

Table-II: Distribution of patients by diagnosis and type of admission ( $n=162)$

\begin{tabular}{|c|c|c|}
\hline \multirow[t]{2}{*}{ Diagnosis } & \multicolumn{2}{|c|}{ Type of Admission } \\
\hline & Emergency & Routine \\
\hline Acute appendicitis & 16 & 0 \\
\hline Appendicular lump & 7 & 0 \\
\hline Blunt trauma abdomen & 3 & 0 \\
\hline Calculous cholecystitis & 5 & 0 \\
\hline Cholelithiasis & 0 & 3 \\
\hline Extremity trauma & 20 & 0 \\
\hline Foreign body swallow & 15 & 0 \\
\hline Head injury & 15 & 0 \\
\hline UDT & 3 & 0 \\
\hline Inguinal hernia & 0 & 15 \\
\hline Omphalocele & 3 & 0 \\
\hline Paraphimosis & 5 & 0 \\
\hline Phimosis & 0 & 15 \\
\hline Scald/burn & 18 & 0 \\
\hline Tongue tie & 0 & 8 \\
\hline Intussusception & 3 & 0 \\
\hline Other & 8 & 0 \\
\hline Total-162(100\%) & $121(74.67 \%)$ & $41(25.33 \%)$ \\
\hline
\end{tabular}

Table-III: Distribution of patients by diagnosis and type of treatment ( $n=162)$

\begin{tabular}{|l|c|c|c|c|}
\hline \multirow{2}{*}{ Diagnosis } & \multirow{2}{*}{$\begin{array}{c}\text { Total } \\
\end{array}$} & \multicolumn{2}{c|}{ Operative management } & Conservative \\
\cline { 3 - 4 } & Patients & Emergency & Elective & management \\
\hline Acute appendicitis & 16 & 16 & 0 & 0 \\
\hline Appendicular lump & 7 & 0 & 0 & 7 \\
\hline Blunt trauma abdomen & 3 & 1 & & 2 \\
\hline Calculous cholecystitis & 5 & 0 & 0 & 5 \\
\hline Cholelithiasis & 3 & 0 & 3 & 0 \\
\hline Extremity trauma & 20 & 20 & 0 & 0 \\
\hline Foreign body swallow & 15 & 0 & 0 & 15 \\
\hline Head injury & 15 & 4 & 0 & 11 \\
\hline UDT & 3 & 0 & 3 & 0 \\
\hline Inguinal hernia & 15 & 0 & 15 & 0 \\
\hline Omphalocele & 3 & 1 & 0 & 2 \\
\hline Paraphimosis & 5 & 5 & 0 & 0 \\
\hline Phimosis & 15 & 0 & 15 & 0 \\
\hline Scald/burn & 18 & 14 & 4 & 0 \\
\hline Tongue tie & 8 & 0 & 8 & 0 \\
\hline Intussusception & 3 & 2 & 0 & 1 \\
\hline Others & 8 & 6 & 2 & \\
\hline Total & $162(100 \%)$ & $69(42.59 \%)$ & $50(30.86 \%)$ & $43(26.54 \%)$ \\
\hline
\end{tabular}

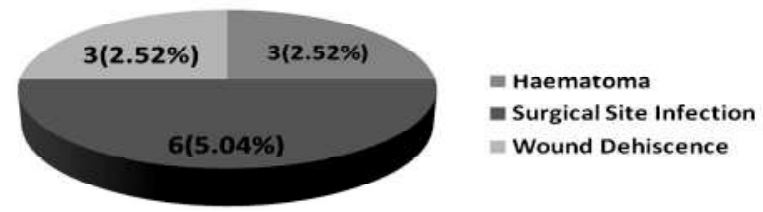

Figure-1: Distribution of patients by type of complications after operative management $(n=119)$

Table-IV: Distribution of patients by outcome after management $(n=162)$.

\begin{tabular}{|l|r|r|r|}
\hline \multicolumn{1}{|c|}{ Aetiology } & Survived (\%) & Died (\%) & Total (\%) \\
\hline Acute appendicitis & $16(100 \%)$ & 0 & $16(100 \%)$ \\
\hline Appendicular lump & $7(100 \%)$ & 0 & $7(100 \%)$ \\
\hline Blunt trauma abdomen & $3(100 \%)$ & 0 & $3(100 \%)$ \\
\hline Calculous cholecystitis & $5(100 \%)$ & 0 & $5(100 \%)$ \\
\hline Cholelithiasis & $3(100 \%)$ & 0 & $3(100 \% 0$ \\
\hline Extremity trauma & $19(95 \%)$ & $1(5 \%)$ & $20(100 \%)$ \\
\hline Foreign body swallow & $15(100 \%)$ & 0 & $15(100 \%)$ \\
\hline Head injury & $14(93.33 \%)$ & $1(6.66 \%)$ & $15(100 \%)$ \\
\hline UDT & $3(100 \%)$ & 0 & $3(100 \%)$ \\
\hline Inguinal hernia & $15(100 \%)$ & 0 & $15(100 \%)$ \\
\hline Intussusception & $3(100 \%)$ & 0 & $3(100 \%)$ \\
\hline Omphalocele & $2(66.66 \%)$ & $1(33.33 \%)$ & $3(100 \%)$ \\
\hline Paraphimosis & $5(100 \%)$ & 0 & $5(100 \%)$ \\
\hline Phimosis & $15(100 \%)$ & 0 & $15(100 \%)$ \\
\hline Scald/burn & $18(100 \%)$ & 0 & $18(100 \% 0$ \\
\hline Tongue tie & $8(100 \%)$ & 0 & $8(100 \%)$ \\
\hline Others & $5(62.55)$ & $3(37.55)$ & $8(100 \%)$ \\
\hline Total & $156(96.29 \%)$ & $6(3.70 \%)$ & $162(100 \%)$ \\
\hline
\end{tabular}




\section{Discussion}

The study analysis showed many pediatrics surgical patients are coming to peripheral hospital and managing there. There were 175 pediatric surgical admission representing $18.69 \%$ of the total pediatric admissions which is similar to other study ${ }^{9}$ where $15.5 \%$ were total pediatric surgical admission. In the study area predominant admitted children are with emergency conditions, emergency admission $121(74.67 \%)$ and routine admission 41(25.33\%), same as other study ${ }^{10}$ which showed emergency cases were predominating (73.13\%) and elective cases were less common (26.26\%) but different from other studies $^{6,11}$ finding, this explains that unlimited for emergency admission and/or refer these children very difficult due to far distance nearby territory hospital with better facility. In this study admission due to congenital anomalies was $36(22.22 \%)$ which is more than other study ${ }^{9}$ where congenital anomalies were $12.6 \%$. Study also show boys were predominant in numbers comparing with girls ${ }^{6,9}$ it is due to boys more vulnerable for inguinal hernias ${ }^{11}$ and trauma that were common presentation in this study. In this study $75.3 \%$ of the children needed a surgical procedure which is nearly similar to other study ${ }^{9}$ findings where $66.7 \%$ needs surgical procedure. The majority of patients were managed operatively, 69(42.59\%) were operated emergently, routine operation $50(30.86 \%)$ and conservative management $43(26.54 \%)$ but different from other study ${ }^{12}$ where majority of patients were managed nonoperatively, with only $35 \%(n=392)$ of patients underwent surgery. Of the 392 patients who underwent operations, $87(22 \%)$ were operated emergently. In this study, most common injuries diagnosis were fractures in $20(12.34 \%)$, burns in 18(11.11\%) and acute appendicitis 16(9.87\%) which is a little different from the other study ${ }^{10}$ where most common injuries diagnosis were fractures $15.6 \%$, soft tissue injuries $8.2 \%$ and burns $5.9 \%$ patients. The most common procedure was reduction and immobilization of fractures in $20(12.34 \%)$ which is similar to the other study ${ }^{9}$ where the most common procedure was reduction and immobilization of fractures in $23.6 \%$ cases. Also was documented in a study in Tanzania ${ }^{13}$ and Malawi ${ }^{14}$. In this study all ingested foreign bodies ${ }^{15}$ pass spontaneously through the gastrointestinal tract without causing injury, patients age range was 2-12 yrs and average age was 4.06 years and male to female ratio is $2: 1$, which is more or less similar to other study ${ }^{15}$ where majority of ingested foreign bodies pass spontaneously through the gastrointestinal tract without causing injury however, according to Louie and Bradin $^{16}, 10-20 \%$ will require nonsurgical intervention and less than $1 \%$ will require surgery. Also the age range and gender preponderence is similar to other study ${ }^{15}$. These findings are consistent with other reports such as the ones of Adhikari and other authors regarding age and gender distribution ${ }^{17,18}$. Procedure was required in 133 cases and among them complications was found in $12(10.08 \%)$ cases; maximum is wound infection in $6(5.04 \%)$ cases. In this study mortality was $6(3.70 \%)$ which is little more than the other study ${ }^{14}$ there were 3 deaths giving a mortality of $2.2 \%$. Among the neonate patients' one case of gastroschisis, one case of omphalocele and intestinal atresia patients were referred to tertiary hospital for operative procedure but the patients expired after operation. One case of gastroschisis expired before referrel.

\section{Conclusion}

This study showed pattern of pediatrics admission and out come after operation at peripheralhospital. The study noticed many children with surgical diseases can be managed at peripheral hospital. To decrease burden of tertiary level hospitals, and to give a better service to children with surgical illness the set up of peripheral hospital should improve specially for the management of neonates. Quality of service also can be increased by trained pediatric anaesthesiologist who is giving service at peripheral hospital.

\section{References}

1. Graham RJ. Specialty services for children with special health care needs: Supplement and not supplant of the medical home. Arch Dis Child 2008; 93:2-4.

2. Nwomeh BC, Mshelbwala PM. Paediatric surgical specialty: how relevant to Africa? Afr J Paediatr Surg 2004; 1:36-42.

3. Raffens per ga TG ed, Swensons Pediatric Surgery, 5th ed Norwalk,Conn: Appleton and Lange; 1990.

4. Siberry Gk ,lannone K, eds .The Harriet Lane Handbook,15th ed. St Louis, Mosby; 2000.

5. Bacley LS, Hoekelman KA, Bates B. Bates Guide to Physical Examination and History Taking. Philadelphia, Pa: Lippincott , Williams and Wikkilis; 1995.

6. Derebew M, Ahmed E. The pattern of pediatrics surgical conditions in TikurAnbessa Hospital, Addis Ababa, Ethiopia. EMJ 2006; 44:331-8.

7. Belachew T, Analysis of admission to the Ethio-Swedish pediatrics clinic. EMJ 1973; 11:3-11.

8. Abebe $G$, Mariam A. Two year retrospective review of reason for pediatrics admission to Chiro hospital eastern Ethiopia. EMJ 2005; 43:241-3.

9. Olasinde A, Oluwadiya K, Akinkuolie A et al. Paediatric Surgical Admissions in a Tertiary Hospital in Western Nigeria. The Internet Journal of Pediatrics and Neonatology 2004; 5(2):1-6. 
10. Tekle TT, Mallalegne TM. Pattern of Pediatric Surgical admission in Yirgalen Hospital Southern Ethiopia. J Vas Med Surg 2016; 4:239.

11. Thomas RW, Thomas FT, Martin SK Groin hernia and hydrocele. In: Keith WA, George WH, Patrick JM (eds.) 2005, Pediatric Surgery.

12. Kendig CE, Samuel JC, Varela $C$ et al, Pediatric Surgical Care in Lilongwe, Malawi: Outcomes and Opportunities for Improvement, J Trop Pediatr 2014; 60(5):352-7.

13. Shija JK, Omar Os. Trauma as a major pediatric surgical problem in Dar-es - Salaam. Proceedings of the association of Surgeon of East Africa. 1980; 3:160-70.

14. Simmons D Accidents in Malawi. Arch Dis Child.1985; 60:65.
15. Diaconescu S, Gimiga N, Sarbu I et al. Foreign Bodies Ingestion in Children: Experience of 61 Cases in a Pediatric Gastroenterology Unit from Romania. Gastroenterol Res Pract 2016; 2016:1982567.

16. Louie MC and Bradin S. Foreign body ingestion and aspiration. Pediatrics in Review 2009; 30(8):295-301.

17. Adhikari P, Shrestha B L, Baskota et al. Accidental foreign body ingestion: analysis of 163 cases," International Archives of Otorhinolaryngology 2007; 11(3):267-70.

18. Susy Safe Working Group. The Susy Safe project overview after the first four years of activity. (2013) International Journal of Pediatric Otorhinolaryngology 2013; 76(1):3-11. 